Article

Process Intensification of

\title{
Dichlorodiphenyltrichloroethane Detection Methods for Determining Trace Concentrations in Soils
}

\author{
Jinghan Zhao $\mathbb{D}$, Stephen Vanderburgt, Rafael M. Santos $\mathbb{D}$ and Yi Wai Chiang *(D) \\ School of Engineering, University of Guelph, 50 Stone Road East, Guelph, ON N1G 2W1, Canada; \\ jzhao11@uoguelph.ca (J.Z.); svanderb@uoguelph.ca (S.V.); santosr@uoguelph.ca (R.M.S.) \\ * Correspondence: chiange@uoguelph.ca; Tel.: +1-519-824-4120 (ext. 58217)
}

Received: 27 May 2020; Accepted: 16 June 2020; Published: 26 June 2020

\begin{abstract}
Dichlorodiphenyltrichloroethane (DDT) residue in Ontario soil is expected to be found at trace levels, since it has been banned for over 45 years in Canada. This presents challenges to the efficiency and accuracy of conventional detection methods. This study intensified the conventional DDT detection method, in the characterization of aged soil samples collected from historically-treated sites in Ontario. Recovery, time consumption, and labor intensity were considered for the intensification evaluation. Ultrasonic probe extraction was found to significantly shorten the extraction time, with similar yield compared to ultrasonic water bath extraction and homogenized extraction. Homogenized extraction for $24 \mathrm{~h}$ following ultrasonic probe extraction can increase yield over $27 \%$. Rotary evaporator concentration was used, since it can reduce the operating time with comparable recovery. The Florisil clean-up column used in the conventional method was removed from the intensified method, due to its negligible effect and high time consumption. The intensified method may be valuable for further investigation to determine other trace level organochlorine pesticide residues in soil samples.
\end{abstract}

Keywords: persistent organic pollutants; organochlorine pesticides; DDT; ultrasonic probe extraction; soil analysis; process intensification

\section{Introduction}

Persistent organic pollutants (POPs) are a major concern in the environmental community, due to their long-term harm to both wildlife and humans [1]. One well-known example is dichlorodiphenyltrichloroethane (DDT), which is a useful broad-range pest control agent in agriculture and forestry, and it can be applied to control the spread of diseases, such as malaria, through the extermination of mosquitoes [2]. It was used extensively from the 1940s to the 1970s in Canada for agricultural and residential purposes [3]. Due to its potential adverse health effects, DDT was banned in the early 1970s in most northern countries, including Canada [4]. However, DDT and its metabolites (namely DDD and DDE) are highly persistent in the environment, and, as a result, many areas that have not seen any DDT use for decades still have measurable DDT concentrations in the soil and water $[5,6]$. Soil is considered to be the major sink of DDT because it is highly hydrophobic [7]. After over 45 years of being banned, DDT is considered to be mostly degraded in the environment, because its half-life was expected to be between two to fifteen years in soil [4].

Several studies were carried out to investigate the soil DDT residual concentrations in Canadian lands from 1994 to 2006. Harris et al. determined the DDT concentration of an agricultural area located in southwestern Ontario in 1994; where historically treated by DDT, the sum concentration of DDT and its metabolites (DDTs) was at $7100 \pm 3000 \mu \mathrm{g} / \mathrm{kg}$ in surface soil [5]. Another study investigated the 
DDT level in a national park in 1999, and the concentration of DDT was at $128 \mu \mathrm{g} / \mathrm{kg}$ [8]. A former agricultural area located in Ontario was also documented to have $9910 \mu \mathrm{g} / \mathrm{kg}$ DDT in soil, according to a study in 2006 [3]. However, limited studies were presented on DDT distribution in Ontario soil in recent years; hence, the current DDT residual level is unknown. Further studies of DDT residual level in soil are still of interest to have a better understanding of the fate of DDT in the historically treated fields over long timeframes. Moreover, DDT concentration is expected to be low in countries that have banned DDT for years, and thus characterization of soils requires the intensification of detection methodologies to recover trace DDT from weathered soils.

Many methodologies have been investigated for the analysis of various organochlorine pesticides (OCPs). The conventional detection method follows the processes of drying, extraction, clean-up, and gas chromatographic separation [9]. However, OCPs analysis methodologies are continuously being modified to improve efficiency and reliability. Wang et al. [9] compared different extraction methods for OCPs from spiked soil samples that included soxhlet extraction, microwave-assisted extraction (MAE), and accelerated solvent extraction (ASE). The MAE method was recommended by the researchers for DDD extraction considering the higher extraction efficiency; however, the reason behind the higher efficiency was not demonstrated. Additionally, the results also showed that the lowest recovery was achieved from soil samples that had the highest organic content. It implies that organic matter content may impact the extraction efficiency. Another study compared the extraction performance of ultrasonic bath extraction, soxhlet extraction, and shake flask extraction on DDT [10]. The results illustrated that ultrasonic bath extraction was the most suitable extraction technique among all three tested techniques, which could minimize solvent, time, and labor consumption. Furthermore, the ultrasonic extraction method had the lowest operating temperature, which could be an important factor to be considered. According to Samuel and Pillai's research, the degradation and volatilization of DDT are correlated to the temperature [11].

Most studies on detection methods optimization have been conducted by using spiked soil samples which can easily determine the recovery with known concentration [9,10,12]; however, spiked soil samples may behave differently than weathered soil samples during the extraction process. Weathered soil may trap DDT inside their particles; in contrast, the spiked soil samples mainly have DDT residing on their surfaces, which are easier to be contacted and solubilized by solvents. Therefore, studies of methodology development conducted on aged soil samples are more valuable for determining the trace DDT level of treated sites. While there is an abundance of research available comparing different extraction technologies $[9,10,12]$, there is limited research on adopting ultrasonic probe extraction, which has intensive power input and higher potential to break down soil clusters and organic particles in a shorter time. Moreover, to our knowledge, limited studies evaluated the recoveries of OCPs by different concentration methods. Accordingly, the conventional detection process must be intensified to effectively recover trace DDT from weathered soils, while being time- and labor-saving.

The objective of this study is to intensify DDT detection, while characterizing historically-treated soils with trace concentrations. The conventional detection method was the base of the process intensification, which mainly includes six sub-processes: drying, homogenize extraction or ultrasonic bath extraction, filtration, Kuderna-Danish or rotary evaporator concentration, clean-up, and instrumental analysis. Three sub-processes were intensified in our proposed method to achieve high recovery with shorter time and less labor consumption: extraction process, concentration process, and clean-up process. Three extraction methods were compared for extracting DDT from soil samples: ultrasonic probe extraction, ultrasonic bath extraction, and homogenized extraction. The recoveries of rotary evaporator and Kuderna-Danish concentrator were compared, and the efficiency of Florisil clean-up column was also assessed. DDT concentration of five sampled sites, formerly under DDT treatment, were determined by the various methods to identify the most intensified combination. 


\section{Methods and Materials}

\subsection{Soil Sampling}

Soil samples were collected from five sites formerly under tobacco cultivation in Ontario. Five trips of soil sampling were conducted from May to August in 2017. Approximately 40 soil cores were taken from each site, as demonstrated in Figure 1. The sampling site was divided into four lanes symmetrically (Lane 1-Lane 4), and ten cores were taken from each lane at equal distance. All soil cores were collected at 12-inches depth by a tubular soil sampler. The collected soil cores were manually mixed, and then kept in clean zipper bags to transport to the laboratory at the University of Guelph. During transportation, the samples were stored in a cooler, at a temperature below $8{ }^{\circ} \mathrm{C}$, to avoid potential volatilization. The samples were stored in a refrigerator $\left(2-4{ }^{\circ} \mathrm{C}\right)$ before analyses. Samples were analyzed within three weeks after collection. The collected soil samples were characterized for $\mathrm{pH}$, organic matter, and physical classification by the Agricultural and Food Laboratory at the University of Guelph.

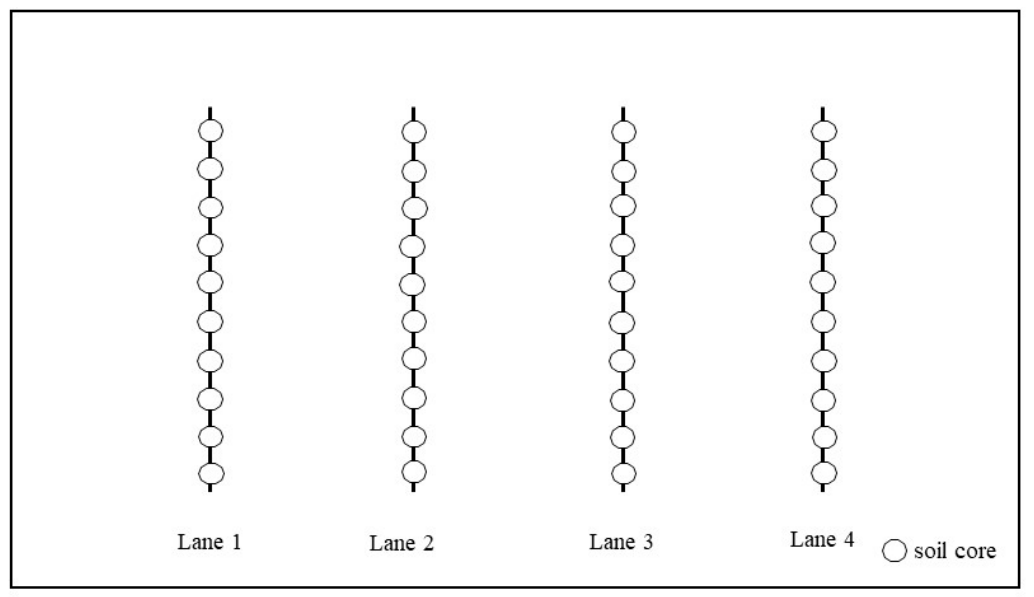

Figure 1. Sampling map of a typical sampling site.

\subsection{Grid Soil Sampling}

Site 4 was selected for additional grid sampling study. Grid soil sampling technique aimed to have a better understanding of how DDT is distributed in a typical sampling site, to account for the effect of hotspots on the experimental results. The method described in Wollenhaupt and Wolkowski's study was followed, and modified according to geological features of the sampling site [13]. As illustrated in Figure 2, a $100 \mathrm{~m}$ by $100 \mathrm{~m}$ square area was outlined at the sampling site for conducting the grid sampling. The marked square area was further divided into nine cells, with even distance between rows and columns. Five soil cores were taken from each cell in a cross pattern, for a total of 45 samples collected from this site. The transportation and storage methods were consistent with Section 2.1. 


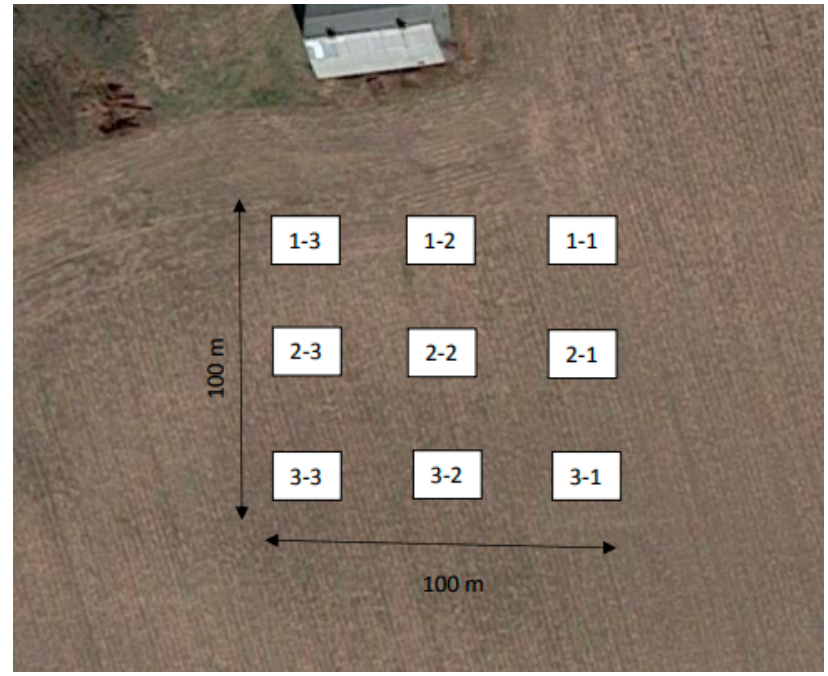

Figure 2. Grid soil sampling map of Site 4.

\subsection{Soil Samples Preparation}

Collected soil samples were dried in a forced-air oven (Binder (Bohemia, NY, USA) FED56) at $40{ }^{\circ} \mathrm{C}$ for $12 \mathrm{~h}$, in Petri dishes with no lids, to remove moisture. The wet mass of each soil sample was between $25-40 \mathrm{~g}$, and the dry mass was recorded accordingly after drying, before further analysis.

\subsection{Conventional and Intensified Extraction Steps}

\subsubsection{Homogenized Extraction (Conventional)}

Homogenized extraction of contaminated soil samples was a conventional chemical extraction method for solid-liquid extraction. The targeted compound was extracted by the selected organic solvent from solid samples [14-16]. Dried soil samples were soaked in $300 \mathrm{~mL}$ n-hexane (Fisher Chemical (Waltham, MA, USA), H3064, 95\%) under room temperature, for $24 \mathrm{~h}$ or $72 \mathrm{~h}$, in $500 \mathrm{~mL}$ glass bottles with caps.

\subsubsection{Ultrasonic Bath Extraction (Conventional)}

Ultrasonic bath extraction is a commonly used extraction method, and it had high yield for extracting DDTs from soil samples, compared with other extraction techniques $[10,12]$. Ultrasonic bath (VWR (Radnor, PA, USA) Symphony 97043-936, $90 \mathrm{~W}$ power) was heated to $40{ }^{\circ} \mathrm{C}$ to extract soil samples, using $300 \mathrm{~mL}$-hexane for either $15 \mathrm{~min}, 30 \mathrm{~min}, 60 \mathrm{~min}$, or $180 \mathrm{~min}$. The dried soil sample was extracted in capped $500 \mathrm{~mL}$ glass bottles with solvent.

\subsubsection{Ultrasonic Probe Extraction (Intensified)}

A Sonics ultrasonic probe processor was used (Sonics \& Materials Inc. (Newtown, CT, USA) VCX $750,750 \mathrm{~W}$ power), fitted with a $19 \mathrm{~mm}$ diameter solid cylindrical probe, operated with $100 \%$ pulse intensity at $50 \%$ duty. A volume of $100 \mathrm{~mL}$ of n-hexane was added to dried soil in an open beaker, and the solution was sonicated for $3 \mathrm{~min}$. This step was repeated three times (after $20 \mathrm{~s}$ pauses for solvent and ice cube additions), resulting in a total pulse time of nine minutes, and a final volume of $300 \mathrm{~mL}$-hexane. Considering the high power input of the ultrasonic probe processor, a cooling jacket with ice cubes was used throughout the extraction to maintain a constant temperature and to avoid overheating (Figure 3). The homogenized extraction method was also conducted on some samples following ultrasonic probe extraction process, for an additional $24 \mathrm{~h}$ or $72 \mathrm{~h}$, to determine the additional yield of diffusion. 


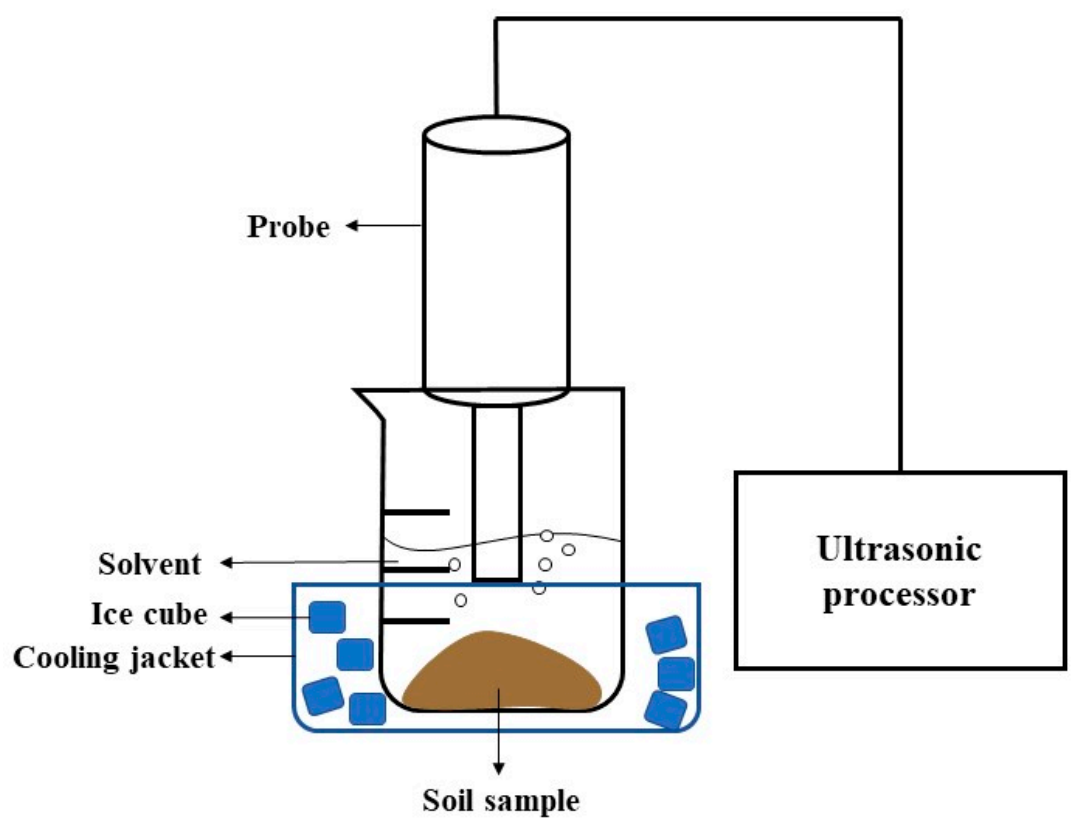

Figure 3. Schematic of the ultrasonic probe extraction setup.

\subsection{Filtration}

Vacuum-assisted filtration was performed after extraction to remove soil particles from the extract. The extract was vacuumed to pass through filter paper (Fisherbrand (Waltham, MA, USA) 09-790-2C) fitted in a funnel, then the filtrated solution was transferred to a clean glass bottle with multiple rinses by solvent to continue the further analyses.

\subsection{Concentration Step}

\subsubsection{Kuderna-Danish Concentration}

4,4'-DDT standards at $250 \mu \mathrm{g} / \mathrm{kg}$ in $10 \mathrm{~mL}$-hexane were prepared, to determine the recovery of Kuderna-Danish (K-D) concentration. The K-D concentrator (Thomas Scientific (Swedesboro, NJ, USA), 4367C53) consists of a three-ball Snyder column, flask, and collection tube. The Snyder column was designed to hold up the evaporated solvent to minimize the analyte loss [17]. The K-D concentrator was pre-wetted by $2 \mathrm{~mL}$-hexane. Then, the K-D concentrator was placed in a water bath, and the temperature was consistently maintained at $100{ }^{\circ} \mathrm{C}$, to accelerate the evaporation speed until the volume was concentrated to $2 \mathrm{~mL}$.

\subsubsection{Rotary Evaporator Concentration}

Again, 4, $4^{\prime}$-DDT standards at $250 \mu \mathrm{g} / \mathrm{kg}$ in $10 \mathrm{~mL}$-hexane were also prepared for determining rotary evaporator concentration recovery. An EYELA Co. Ltd. (Shanghai, China) N-1110 rotary evaporator was operated under vacuum, and with a water bath at $50{ }^{\circ} \mathrm{C}$. The solutions were concentrated by the rotary evaporator to approximately $2 \mathrm{~mL}$. The accurate readings of the concentrated volume were quantified by a graduated pipette for further concentration determination.

\subsection{Florisil Clean-Up Step}

This step followed the EPA method 3620c Florisil clean-up [18]. Florisil, at 60-100 mesh, supplied by Acros Organics (Fair Lawn, NJ, USA) (1343-88-0) was used. Homogenized soil sampled from Site 4 was adopted to determine the existence of interference in the soil samples and the recovery of the clean-up column. Tests were conducted with column and without column, as a comparison. After the clean-up process, samples were concentrated again and transferred to glass vials for GC-MS analysis. 


\subsection{Gas Chromatography-Mass Spectrometry (GC/MS) Analysis}

An Agilent Technologies GC-MS (Santa Clara, CA, USA) with a 5975 inert XL mass selective detector, 7683B series injector, and 6890N Network GC, J\&W Scientific HP-5 (30 m long, $0.32 \mathrm{~mm}$ bore, $0.25 \mu \mathrm{m}$ film) fused-silica column (Folsom, CA, USA) and pure helium gas as a carrier was used for all analyses. Selectivity was obtained by selective ion monitoring (SIM) of $235 \mathrm{~m} / \mathrm{z}$ and $237 \mathrm{~m} / \mathrm{z}$ peaks (characteristic of DDT and DDD), and of $246 \mathrm{~m} / \mathrm{z}$ and $318 \mathrm{~m} / \mathrm{z}$ peaks (characteristics of DDE). DDT, DDD, and DDE concentrations, hereafter denominated DDTs as the sum, were calculated by external reference calibration curves of 4,4'-DDT (Ultra Scientific (Santa Clara, CA, USA) US-PST-280, >95\%), 4, $4^{\prime}$-DDD (SPEX CertiPrep (Metuchen, NJ, USA), S-1075, >98\%), and 4,4'-DDE (SPEX CertiPrep, S-1085, $>98 \%$ ) in n-hexane (standards concentration levels: $10 \mu \mathrm{g} / \mathrm{kg}, 25 \mu \mathrm{g} / \mathrm{kg}, 50 \mu \mathrm{g} / \mathrm{kg}, 100 \mu \mathrm{gg} / \mathrm{kg}, 250 \mu \mathrm{g} / \mathrm{kg}$, $500 \mu \mathrm{g} / \mathrm{kg}, 1000 \mu \mathrm{g} / \mathrm{kg}$, and $2000 \mu \mathrm{g} / \mathrm{kg}$ ). Calibration curves for DDT, DDD, and DDE are shown in Figures S1-S3, respectively, in the Supplementary Materials. GC-MS parameters were adapted from EPA method 8270d Semivolatile Organic Compounds by Gas Chromatography/Mass Spectrometry (GC/MS) and 8081b Organochlorine Pesticides by Gas Chromatography [19,20]. SIM parameters were adapted from Raina and Hall [21]. The applied parameters are shown in Table 1.

Table 1. GC/MS parameters.

\begin{tabular}{cc}
\hline Parameters & Values/Settings \\
\hline Scan Time & $<1 \mathrm{~s} / \mathrm{scan}$ \\
\hline Initial temperature & $130{ }^{\circ} \mathrm{C}$, hold $4 \mathrm{~min}$ \\
\hline Temperature program & $130-300{ }^{\circ} \mathrm{C}$ at $30{ }^{\circ} \mathrm{C} / \mathrm{min}$ \\
\hline Final temperature & $300{ }^{\circ} \mathrm{C}$, hold $2 \mathrm{~min}$ \\
\hline Injector temperature & $280{ }^{\circ} \mathrm{C}$ \\
\hline Transfer line temperature & $280{ }^{\circ} \mathrm{C}$ \\
\hline Injection volume & $1 \mu \mathrm{L}$ \\
\hline Pulsed splitless inlet program & $9.5 \mathrm{psi}, 45.1 \mathrm{~mL} / \mathrm{min} \mathrm{He}$ \\
\hline Injection pulse pressure & $50 \mathrm{psi} \mathrm{until} 1.50 \mathrm{~min}$ \\
\hline Purge flow to split vent 4 & $40 \mathrm{~mL} / \mathrm{min}$ at $2 \mathrm{~min}$ \\
\hline
\end{tabular}

The blank solvent was tested first, and showed that the solvent had no interference on the results. All standards and samples were injected three times during the run, and the average abundance was applied in the quantification. The blank solvent was also injected between each sample, to eliminate potential cross-contamination. The correlation coefficient of external standards was consistently over 0.99. Limit of detection (LOD) and limit of quantification (LOQ) were determined following a documented method [22], at $3.5 \mu \mathrm{g} / \mathrm{kg}$ and $10 \mu \mathrm{g} / \mathrm{kg}$, respectively.

\subsection{Replication and Statistical Analysis}

All extraction, concentration, and clean-up experiments were conducted in triplicate, and average yields, recoveries, and efficacies were determined. Statistical analysis was performed for understanding the results of the grid soil sampling study. Dixon's test was performed to identify outliers. The normality of the DDTs concentration in the grid sampling was determined using the Shapiro-Wilk test.

\section{Results and Discussion}

\subsection{Soil Characterization}

The characterization of the collected soils is presented in Table 2. The soils sampled from former tobacco sites were particularly sandy, and the organic matter content was in the range of $1.2 \%$ to 
1.6\%. As discussed, organic matter tends to bind with DDTs, and sandy loam soil is harder to be extracted $[9,23]$. Therefore, Site 4 was considered to have the most suitable soil for verification of the intensification methodology, due to its soil texture and high organic content. The soil $\mathrm{pH}$ values were in a narrow range, from 6.07 to 6.50, and its effect on DDT detection has not been demonstrated in documented studies. Furthermore, the $\mathrm{pH}$ value of Site 4 was moderate among all the sampled sites, making it ideal for experiments to verify the method intensification.

Table 2. Soil characterization of five sampling sites.

\begin{tabular}{cccccccc}
\hline \multirow{2}{*}{ Site Name } & $\mathbf{p H}$ & \multirow{2}{*}{$\begin{array}{c}\text { Organic Matter } \\
\text { (\% Dry) }\end{array}$} & \multicolumn{3}{c}{ Particle Size Distribution (\%) } & \multicolumn{2}{c}{ Texture } \\
\cline { 4 - 7 } & & & Gravel & Sand & Silt & Clay & \\
\hline Site 1 & 6.5 & 1.4 & 0.2 & 90.1 & 4.9 & 4.9 & Sand \\
\hline Site 2 & 6.36 & 1.3 & 0.3 & 83 & 9.7 & 7.3 & Loamy Sand \\
\hline Site 3 & 6.12 & 1.6 & 0.2 & 88.5 & 5.7 & 5.7 & Sand \\
\hline Site 4 & 6.26 & 1.6 & 1.8 & 74.9 & 15.9 & 9.2 & Sandy Loam \\
\hline Site 5 & 6.07 & 1.2 & 0.5 & 90.4 & 4.0 & 5.6 & Sand \\
\hline
\end{tabular}

\subsection{Process Intensification on Extraction Step}

Homogenized extraction is a conventional method for pesticide extraction, and it is considered to be less efficient, since it works by diffusion with no physical acceleration [16]. Ultrasonic bath extraction is another common method used for OCPs extraction [24-26], and has been demonstrated to have higher efficiency on extracting OCPs from soil samples [10]. Therefore, the ultrasonic bath extraction was also selected to be the starting point of the process intensification on the extraction step. Ultrasonic probe extraction is a less-studied method, compared with the ultrasonic bath, in the development of extraction methodology for pesticide detection. Available studies of its application mostly relate to extracting analytes from biological samples, and there is limited data on its extraction yield of pesticides from soil samples [27-29]. Accordingly, the extraction process was intensified by comparing the extraction performance of these three techniques, and determining the co-extraction effects.

Sampled soil from Site 4 was used for extraction method intensification. Three techniques corresponded to nine conditions: homogenized extraction for $24 \mathrm{~h}$ (HE-24), homogenized extraction for $72 \mathrm{~h}$ (HE-72), ultrasonic water bath extraction for $0.25 \mathrm{~h}$ (UB-0.25), ultrasonic water bath extraction for $0.5 \mathrm{~h}$ (UB-0.5), ultrasonic water bath extraction for one hour (UB-1), ultrasonic water bath extraction for three hours (UB-3), ultrasonic probe extraction for nine minutes (UP-9), ultrasonic probe extraction for nine minutes plus $24 \mathrm{~h}$ of homogenized extraction (UPHE-24), and ultrasonic probe extraction for nine minutes plus $72 \mathrm{~h}$ of homogenized extraction (UPHE-72). The extracts were then processed by rotary evaporator concentration and GC-MS analysis, and the extracted concentrations were determined. The yield of DDTs from soil by each extraction method is demonstrated in Figure 4.

The retention time was positively correlated to the extraction recoveries for all the techniques adopted. For homogenized extraction, prolonging the retention time from $24 \mathrm{~h}$ to $72 \mathrm{~h}$ increased the yield by $22.3 \%$. Longer extraction time of ultrasonic water bath also enhanced the extraction performance accordingly. However, three hours of ultrasonic water bath extraction can extract more targeted analyte than $24 \mathrm{~h}$ soaking, and the results also showed comparable extraction efficiency for nine minutes of ultrasonic probe extraction versus $72 \mathrm{~h}$ soaking. Therefore, using ultrasonic extraction could shorten the extraction time significantly. According to a published study, ultrasonic bath extraction was an effective extraction method to extract DDTs from aged soil samples, compared with other extraction methods [10]. Ultrasonic bath can break down weathered soil particles and increase the contact between solvent and trapped DDT by acoustic cavitation [30]. Meanwhile, heating can also accelerate the diffusion rate and increase the solvent's capacity of solubilizing more analytes. 


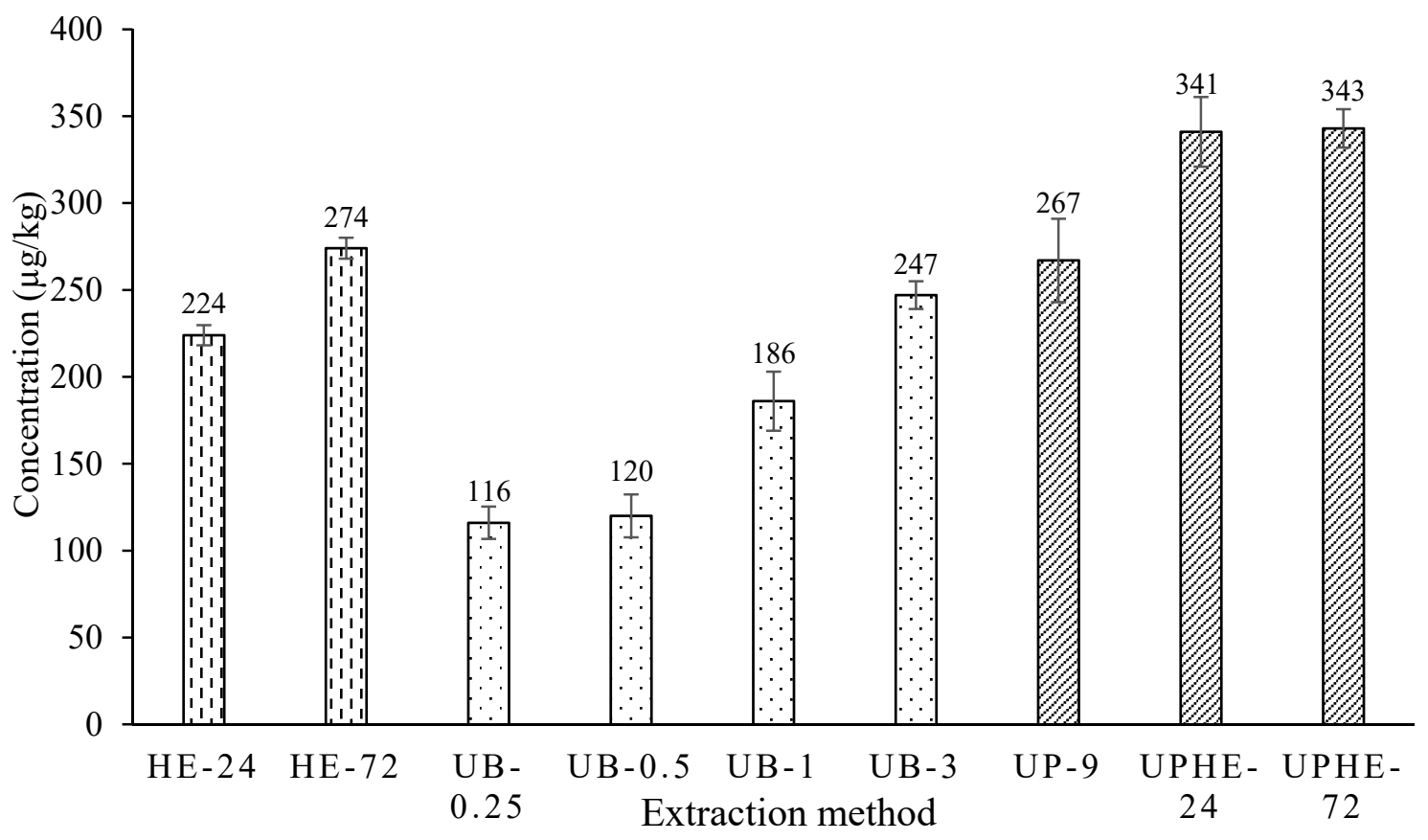

Figure 4. Extracted dichlorodiphenyltrichloroethane (DDTs) concentration of Site 4 soil, by different extraction methods.

By comparing the ultrasonic bath extraction and ultrasonic probe extraction, three hours of water bath sonication yield ( $247 \pm 8 \mu \mathrm{g} / \mathrm{kg}$ ) was slightly lower, compared to using an ultrasonic probe for nine minutes at $267 \pm 24 \mu \mathrm{g} / \mathrm{kg}$. The power of ultrasonic probe extraction can be 100 times higher than the ultrasonic bath, which can speed up the process of solid-liquid extraction significantly [31]. The higher power of the ultrasonic probe may be able to break apart resilient particles that an ultrasonic water bath cannot. However, ultrasonic probe extraction on its own was not enough to extract all the DDT contained in the soil, as shown in the results. A further soaking for $24 \mathrm{~h}$ after extraction appeared to increase recovery significantly. It has been theorized that aged DDT in the soil is found deeply-bound through hydrophobic adsorption in organic and humic soil materials [32]. A longer solvent contact time could liberate more of the deeply-held DDT into solution.

In an efficient lab, after ultrasonic extraction, the soil may be removed immediately from the extracting solvent by filtration. This would result in a very short solvent contact time with the soil. For maximizing the extraction yield, the added step of soaking the sample in hexane was quite efficient, and it required no energy or labor. This step increased the yield by around $30 \%$. Therefore, it is recommended that soaking should be added to soil DDTs extraction procedures to increase the solubilizing of analytes in the solvent. Based on this comparison, the ultrasonic probe extraction was chosen for its speed, and the ability to break apart soil particles to allow the release of deeply-bounded DDT through enhanced mass transfer between soil solids and liquid solvent, and it was followed by $24 \mathrm{~h}$ homogenized extraction for all further analyses in this research.

\subsection{Process Intensification on Concentration Step}

For trace analysis, the soil extract needs to be concentrated down to a small volume for GC-MS analysis. K-D concentrator and rotary evaporator are commonly used apparatus for OCPs analysis, to concentrate down volatile organic solvents [8-10]. The process intensification on the concentration step was conducted by comparing their recovery, time, and labor consumption. This step was intensified mainly because DDT is a semi-volatile compound that may volatilize during the concentration. Therefore, comparing and determining the recovery of different concentration techniques can enhance the detection method performance and minimize the loss of DDT, especially for concentrating trace levels of analytes as in this study. 
The K-D concentrator uses heating and a Snyder column to reduce targeted analyte loss from the evaporation of solvent. Rotary evaporation uses reduced pressure to lower the boiling point of the solvent and evaporates with slight heating in a greatly reduced evaporation time. The average recovery of K-D concentration was $84.01 \pm 0.93 \%$, while an average recovery of $83.22 \pm 7.9 \%$ was obtained by using the rotary evaporation concentration method. In comparison to rotary evaporation, K-D concentration had a comparable recovery, but the disadvantage of K-D concentration is the extremely large amount of time required to concentrate the sample. The average concentration speed for the K-D concentrator using n-hexane was slow, at approximately $15 \mathrm{~min} / \mathrm{mL}$. For rotary evaporation, the evaporation was efficient, at approximately $2 \mathrm{~s} / \mathrm{mL}$. Furthermore, K-D concentrator needs to be operated under boiling water so that the solvent can be heated by steam. One study showed that the volatilization and degradation rates of DDT were positively correlated to the ambient temperature [11]. Therefore, higher temperatures $\left(100{ }^{\circ} \mathrm{C}\right.$ versus $\left.50^{\circ} \mathrm{C}\right)$ could result in the possible volatilization and degradation of DDTs during the process. After comprehensive consideration of the intensification criteria, rotary evaporation was chosen as the concentration method, based on its 450 times greater speed of evaporation, lower temperature, and similar recovery to K-D concentration.

\subsection{Process Intensification on Clean-Up Step}

A Florisil clean-up column is meant to separate DDTs from other n-hexane soluble compounds that are in the soil, such as alkanes and other PCBs, and is a conventional clean-up process approved by EPA [18]. For intensifying the process, by minimizing the time consumption and labor intensity with comparable recovery, the efficiency of the Florisil clean-up column was evaluated. The results of the GC-MS SIM scan appeared identical for the same soil analyzed with, or without, Florisil clean-up column, as well as the calculated concentrations, which are shown in Table 3. The difference of these results is not statistically significant, though cleaned up concentration was slightly higher and with less variation, as would be expected. Therefore, in the interest of saving time, it is possible to omit the clean-up column stage from the procedure for the specific soil studied, with low loss of precision. It may be that modern advanced GC-MS techniques make the Florisil column clean-up less necessary, for some soils, by utilizing enhanced selectivity programs, such as GC-MS SIM. Another potential reason is that the historically applied pesticides of the tested sites have significantly different structures and properties from DDTs; therefore, the interference is minor in this study. However, the efficiency of Florisil clean-up process should be reevaluated in other studies, since the pesticide application history and soil type varies.

Table 3. Florisil clean-up column recovery test for Site 4 soil.

\begin{tabular}{cc}
\hline Methods & Mean DDTs $(\mu \mathrm{g} / \mathbf{k g})$ \\
\hline No Column & $96 \pm 12$ \\
\hline With Column & $98 \pm 5$ \\
\hline
\end{tabular}

\subsection{Grid Soil Sampling Results}

Grid soil sampling was performed at Site 4 to examine the accuracy and reliability of the further DDTs concentration determination. This sampling method is commonly used for crop nutrient management and site assessment [13]. The grid sampling results are demonstrated in Figure 5. The 95\% confidence interval of DDTs concentration in Site 4 was between $25.90 \mu \mathrm{g} / \mathrm{kg}$ to $78.60 \mu \mathrm{g} / \mathrm{kg}$, according to the Shapiro-Wilk test result. Furthermore, the DDTs concentration in location 1-3 appeared to be higher than the rest of the data, at $248 \mu \mathrm{g} / \mathrm{kg}$, which implicates that hotspots may exit in sampling sites. The variability could be caused by complicating factors such as cultivation, translocation, and heterogeneous pesticide spray. Enough samples should be collected from each sampling site to minimize the variability and to increase the representativeness of samples. 


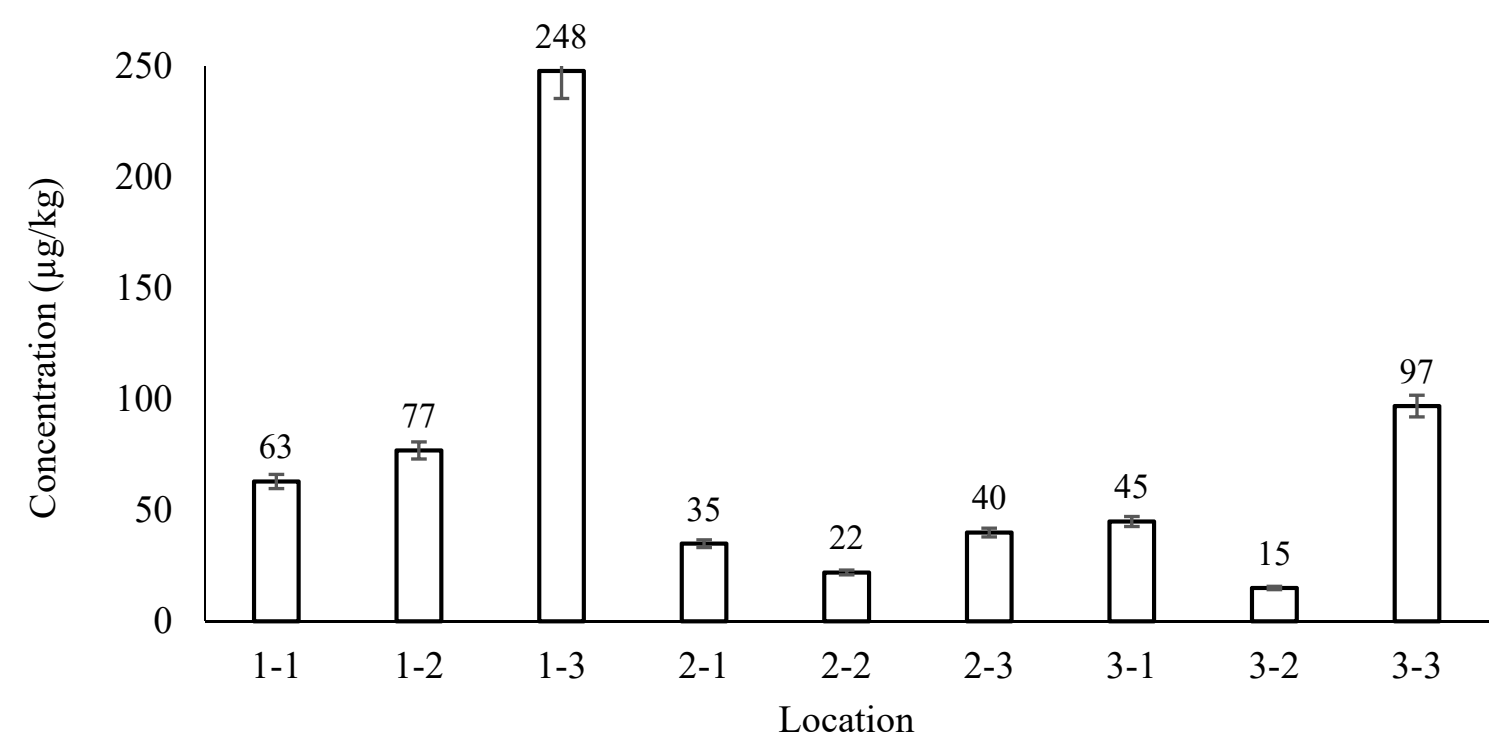

Figure 5. DDTs concentration of grid soil sampling cells in Site 4.

\subsection{Residual DDTs in Sampled Sites Determined by the Intensified Method}

The intensified methodology consists of extracting soil samples by the ultrasonic probe for nine minutes and letting the extract soak for $24 \mathrm{~h}$ in the solvent. After that, the soil particles were removed by filtration, and the filtrated solution was concentrated by rotary evaporator to a small volume for GC-MS analysis, with no use of Florisil clean-up. The intensified method can maximize extraction yield, reducing operating time and labor. Using the intensified method, the DDTs residual concentration of five sampled sites was determined, as presented in Table 4 .

Table 4. DDTs concentration of sites formerly under tobacco cultivation in Ontario.

\begin{tabular}{cc}
\hline Site Name & Mean DDTs $(\mu \mathrm{g} / \mathbf{k g})$ \\
\hline Site 1 & $114 \pm 26$ \\
\hline Site 2 & $108 \pm 14$ \\
\hline Site 3 & $341 \pm 20$ \\
\hline Site 4 & $96 \pm 23$ \\
\hline Site 5 & $95 \pm 16$ \\
\hline
\end{tabular}

\section{Conclusions}

Soil samples were collected from five sites formerly under tobacco cultivation in Ontario. Site 4 was selected for verification of the intensified method, as it has high organic content and sandy loam texture. Three sub-processes were intensified (extraction process, concentration process, and clean-up process), based on three process intensification criteria: high recovery, time efficiency, and labor-saving. Homogenized extraction, ultrasonic water bath extraction, and ultrasonic probe extraction were compared for extraction recoveries. Ultrasonic probe extraction was found to be the most efficient method for extracting DDTs from the soil. Modifying the extraction process to include a 24-h long soak of the soil in solvent after ultrasonic probe extraction was found to greatly increase the yield. The rotary evaporator was selected for concentrating extract, due to it significantly reducing the operational time with comparable recovery. The standard Florisil clean-up column was found to be unnecessary, as the GC-MS SIM scan gave sufficient selectivity with, or without, the clean-up column in this study. The DDTs concentration of soil samples collected from five sites were determined by the intensified method, and the methodology could potentially be applied in the analysis of other trace levels of OCPs 
in aged soils. A long-term study of some of the sampled sites is still ongoing, to better understand the residual levels, distribution, and rate of degradation of DDTs in Southern Ontario.

Supplementary Materials: The following are available online at http://www.mdpi.com/2673-4079/1/1/6/s1, Figure S1: The calibration curve of standard DDT solutions, Figure S2: The calibration curve of standard DDD solutions, Figure S3: The calibration curve of standard DDE solutions.

Author Contributions: Conceptualization, Y.W.C; Methodology, J.Z, S.V., Y.W.C.; Investigation, J.Z., S.V.; Resources, Y.W.C.; Writing—Original Draft Preparation, J.Z.; Writing-Review \& Editing, R.M.S., Y.W.C.; Supervision, Y.W.C., R.M.S.; Project Administration, Y.W.C.; Funding Acquisition, Y.W.C. All authors have read and agreed to the published version of the manuscript.

Funding: Funding was provided by the Ontario Ministry of Agriculture, Food, and Rural Affairs (OMAFRA). Special thanks to Perry Martos, Joanne Ryks, and Ryan Smith for valuable instruction and help.

Conflicts of Interest: The authors declare no conflict of interest.

\section{References}

1. Li, Q.Q.; Loganath, A.; Chong, S.Y.; Tan, J.; Obbard, J.P. Persistent organic pollutants and adverse health effects in humans. J. Toxicol. Environ. Health Part. A 2006, 69, 1987-2005. [PubMed]

2. Rogan, W.J.; Chen, A. Health risks and benefits of bis (4-chlorophenyl)-1, 1, 1-trichloroethane (DDT). Lancet 2005, 366, 763-773. [CrossRef]

3. Crowe, A.S.; Smith, J.E. Distribution and persistence of DDT in soil at a sand dune-marsh environment: Point Pelee, Ontario, Canada. Can. J. Soil Sci. 2007, 87, 315-327. [CrossRef]

4. Persistent Organic Pollutants (POPs) Fact Sheet Series: Dichlorodiphenyltrichloroethane (DDT). Available online: https://www.aadnc-aandc.gc.ca/eng/1316102914633/1316103004743 (accessed on 19 May 2020).

5. Harris, M.; Wilson, L.; Elliott, J.; Bishop, C.; Tomlin, A.; Henning, K. Transfer of DDT and metabolites from fruit orchard soils to American robins (Turdus migratorius) twenty years after agricultural use of DDT in Canada. Arch. Environ. Contam. Toxicol. 2000, 39, 205-220. [CrossRef] [PubMed]

6. Jan, M.R.; Shah, J.; Khawaja, M.A.; Gul, K. DDT residue in soil and water in and around abandoned DDT manufacturing factory. Environ. Monit. Assess. 2009, 155, 31-38. [CrossRef] [PubMed]

7. Wang, X.; Sheng, J.; Gong, P.; Xue, Y.; Yao, T.; Jones, K.C. Persistent organic pollutants in the Tibetan surface soil: Spatial distribution, air-soil exchange and implications for global cycling. Environ. Pollut. 2012, 170, 145-151. [CrossRef] [PubMed]

8. Don Waite, P.B.; Quinnett-Abbott, L.; Ripley, B.D. Residues of DDT and other selected organochlorine pesticides in soils from Saskatchewan, Canada (1999). Can. J. Soil Sci. 2005, 85, 265-271. [CrossRef]

9. Wang, W.; Meng, B.; Lu, X.; Liu, Y.; Tao, S. Extraction of polycyclic aromatic hydrocarbons and organochlorine pesticides from soils: A comparison between Soxhlet extraction, microwave-assisted extraction and accelerated solvent extraction techniques. Anal. Chim. Acta 2007, 602, 211-222. [CrossRef] [PubMed]

10. Tor, A.; Aydin, M.E.; Özcan, S. Ultrasonic solvent extraction of organochlorine pesticides from soil. Anal. Chim. Acta 2006, 559, 173-180. [CrossRef]

11. Samuel, T.; Pillai, M. The effect of temperature and solar radiations on volatilisation, mineralisation and degradation of [14C]-DDT in soil. Environ. Pollut. 1989, 57, 63-77. [CrossRef]

12. Thangavadivel, K.; Megharaj, M.; Smart, R.S.C.; Lesniewski, P.J.; Bates, D.; Naidu, R. Ultrasonic enhanced desorption of DDT from contaminated soils. Water. Air. Soil Pollut. 2011, 217, 115-125. [CrossRef]

13. Wollenhaupt, N.; Wolkowski, R. Grid soil sampling. Better Crops 1994, 78, 6-9.

14. Mauri, R.; Shinnar, R.; d'Amore, M.; Giordano, P.; Volpe, A. Solvent extraction of chromium and cadmium from contaminated soils. AIChE J. 2001, 47, 509-512. [CrossRef]

15. Baskar, G.; Kalavathy, G.; Aiswarya, R.; Selvakumari, I.A. Advances in bio-oil extraction from nonedible oil seeds and algal biomass. In Advances in Eco-Fuels for a Sustainable Environment; Woodhead Publishing: Cambridge, UK, 2019; pp. 187-210.

16. Zubairi, S.I.; Sarmidi, M.R.; Aziz, R.A. A preliminary study of rotenone exhaustive extraction kinetic from Derris elliptica dried roots using normal soaking extraction (NSE) method. Adv. Environ. Biol. 2014, 8, 910-916.

17. Mitra, S.; Patnaik, P.; Kebbekus, B.B. Environmental Chemical Analysis, 2nd ed.; CRC Press: Boca Raton, FL, USA, 2018; ISBN 0-429-85702-0. 
18. US EPA Method 3620C: Florisil Cleanup. Available online: https://www.epa.gov/hw-sw846/sw-846-testmethod-3620c-florisil-cleanup (accessed on 8 June 2020).

19. US EPA Method 8270D: Semivolatile Organic Compounds by Gas Chromatography/Mass Spectrometry. Available online: https://19january2017snapshot.epa.gov/hw-sw846/sw-846-test-method-8270d-semivolatileorganic-compounds-gas-chromatographymass-spectrometry_.html (accessed on 8 June 2020).

20. US EPA Method 8081B: Organochlorine Pesticides by Gas Chromatography. Available online: https://www. epa.gov/hw-sw846/sw-846-test-method-8081b-organochlorine-pesticides-gas-chromatography (accessed on 8 June 2020).

21. Raina, R.; Hall, P. Comparison of gas chromatography-mass spectrometry and gas chromatography-tandem mass spectrometry with electron ionization and negative-ion chemical ionization for analyses of pesticides at trace levels in atmospheric samples. Anal. Chem. Insights 2008, 3, 111-125. [CrossRef] [PubMed]

22. Ambruster, D.; Pry, T. Limit of blank, limit of detection and limit of quantification. Clin. Biochem. Rev. 2008, 29, 49-52.

23. Aislabie, J.; Richards, N.; Boul, H. Microbial degradation of DDT and its residues-A review. N. Z. J. Agric. Res. 1997, 40, 269-282. [CrossRef]

24. Sun, J.; Pan, L.; Zhan, Y.; Lu, H.; Tsang, D.C.; Liu, W.; Wang, X.; Li, X.; Zhu, L. Contamination of phthalate esters, organochlorine pesticides and polybrominated diphenyl ethers in agricultural soils from the Yangtze River Delta of China. Sci. Total Environ. 2016, 544, 670-676. [CrossRef]

25. Wang, B.; Wu, C.; Liu, W.; Teng, Y.; Luo, Y.; Christie, P.; Guo, D. Levels and patterns of organochlorine pesticides in agricultural soils in an area of extensive historical cotton cultivation in Henan province, China. Environ. Sci. Pollut. Res. 2016, 23, 6680-6689. [CrossRef]

26. Dumanoglu, Y.; Gaga, E.O.; Gungormus, E.; Sofuoglu, S.C.; Odabasi, M. Spatial and seasonal variations, sources, air-soil exchange, and carcinogenic risk assessment for PAHs and PCBs in air and soil of Kutahya, Turkey, the province of thermal power plants. Sci. Total Environ. 2017, 580, 920-935. [CrossRef]

27. Albero, B.; Tadeo, J.L.; Pérez, R.A. Ultrasound-assisted extraction of organic contaminants. TrAC Trends Anal. Chem. 2019, 118, 739-750. [CrossRef]

28. Pena-Abaurrea, M.; de la Torre, V.G.; Ramos, L. Ultrasound-assisted extraction followed by disposable pipette purification for the determination of polychlorinated biphenyls in small-size biological tissue samples. J. Chromatogr. A 2013, 1317, 223-229. [CrossRef] [PubMed]

29. Flores-Ramirez, R.; Medellin-Garibay, S.; Castillo, C.; Ilizaliturri-Hernandez, C.; Zuki-Orozco, B.; Batres-Esquivel, L.; Diaz-Barriga, F. Application of focused ultrasound-assisted extraction to the determination of persistent organic pollutants (POPs) in soil samples. Bull. Environ. Contam. Toxicol. 2015, 95, 207-214. [CrossRef]

30. Chandrapala, J.; Oliver, C.M.; Kentish, S.; Ashokkumar, M. Use of power ultrasound to improve extraction and modify phase transitions in food processing. Food Rev. Int. 2013, 29, 67-91. [CrossRef]

31. Bermudez-Aguirre, D. Ultrasound: Advances in Food Processing and Preservation; Academic Press: Cambridge, MA, USA, 2017; ISBN 0-12-804614-7.

32. Gevao, B.; Semple, K.T.; Jones, K.C. Bound pesticide residues in soils: A review. Environ. Pollut. 2000, 108, 3-14. [CrossRef]

(C) 2020 by the authors. Licensee MDPI, Basel, Switzerland. This article is an open access article distributed under the terms and conditions of the Creative Commons Attribution (CC BY) license (http://creativecommons.org/licenses/by/4.0/). 